\section{HONOURS, AWARDS, APPOINTMENTS}

Inspirational individual

Dr Andrew Dawood was awarded the Global Inspirational

Individual Award on 7 November 2013 at the 3D Awards

Ceremony. Dr Dawood has been pioneering the use of 3D

printing in dental implant treatments since 1999.

\section{First British President}

Allan Thom has been elected the first British President of the World Federation of Orthodontists, and will take office at the 8th International Orthodontic Conference in London in 2015.

\section{Gold Medal}

Mandeep Gosal, who recently completed his MSc in Orthodontics at King's College London Dental Institute, has been awarded the 2013 William Houston Gold Medal for achieving the most outstanding performance in the Membership of Orthodontics examination of the Royal College of Surgeons of Edinburgh.

\section{Practice of the year}

Church Court Dental Practice of Dumfries has been awarded the first Dental Practice of the Year award. The prize of $£ 1,500$, sponsored by Dental Protection and schülke, acknowledges hard work and commitment, with a strong focus on risk management and professionalism.

\section{PATRICK COLMAN SWEENEY}

It is with sadness that we report the death of retired consultant dentist Patrick Colman Sweeney, of Bingley, West Yorkshire, on 26 September 2013, aged 51.

\title{
MOUTH CANCER ACTION MONTH ACTIVITY
}

\section{Spinning in Cockermouth}

Staff from Maryport Dental Care

Centre, St Helen's Dental Practice, Helen Siddle Dental Practice and Goodwin Dental Practice joined forces in November to run a fourhour 'Spinathon' on spinning bikes at Cockermouth Leisure Centre, to raise awareness of mouth cancer and collect funds. Two of the practices are offering a limited number of free mouth cancer checks for people who don't have a dentist.

\section{Presentations in Dundee}

Professor Graham Ogden and Mr Kishore Shekar discussed the increasing incidence and changing presentation of mouth cancer at the British Dental Association (BDA) Dundee and Perth District Section's November symposium. Mr Michael Walton explored the social impact of mouth cancer and presented the work of The Ben Walton Trust, a charity founded in memory of his son who died of mouth cancer aged 22 years.

Miss Anja Visser presented the work of Mouth Cancer Awareness Week. For the last 15 years this local committee has campaigned to raise awareness among students at the University of Dundee.

\section{GPs overwhelmed by dental patients}

A survey of more than 1,000 GPs, looking at how patients seeking advice on oral health issues impacts their surgeries, concluded that GPs feel under increasing pressure from patients who are coming to them, rather than their dentists, for oral health related issues. Ninety-six percent think that more should be done to encourage patients to go to their dentist rather than their GP for mouth-related health issues.

The results of the survey, which was commissioned by the Association of Dental Groups (ADG), were released as part of Mouth Cancer Action Month.

\section{Trust Checklist}

Dr Taher Rashid, a restorative and cosmetic dentist in Farnham, Surrey, has published a 'Trust Checklist' and video on his practice's website so that patients 'can be confident that their dentist will detect early signs of mouth cancer' The video can be viewed at: www.timedental.co.uk/blog/.

\section{REDUCING DIETARY SUGARS MUST BE A PRIORITY}

The association between poor oral health and increased risk of cardiovascular disease should make the reduction of dietary sugars an important health policy target, say researchers writing in the Journal of the Royal Society of Medicine.

Junk food and heart disease: the missing tooth (due to be published on 28/11/13) was written by Mohammed Ahmed Rashid and Amardeep Bains and refers to the well-publicised New York ‘soda ban' controversy.

Dr Rashid, of the Department of Public Health and Primary Care, University of Cambridge, said: 'As well as having high levels of fats and salt, junk foods often contain a great deal of sugar and the effect this has on oral health may be an important additional mechanism by which junk food elevates risk of cardiovascular disease. Among different types of junk food, soft drinks have raised particular concerns and are the main source of free sugar for many individuals.'
The authors point out in the article that in the UK, fizzy drinks remain commonly available in public areas ranging from hospitals to school. \section{西}

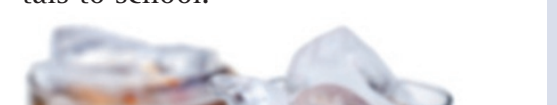

\section{WEST LANCS/CHESHIRE/ NORTH WALES AGM}

All BDA members are cordially invited to attend the West Lancs/West Cheshire and North Wales Branch Annual General Meeting on 11 February 2014. The meeting will include a presentation by Medical Money Management on pensions and personal finances. The venue is PGMC, Clatterbridge Hospital, Bebbington, CH63 4JY, refreshments from $5.45 \mathrm{pm}$, with the lecture and AGM from $6.30 \mathrm{pm}$. To register attendance/apologies please email the Branch Secretary on mrsclayden@yahoo.co.uk. 